\title{
$\nabla$
}

\section{Angioma serpiginosum: report of an unusual acral case and review of the literature*}

\author{
Azael Freites-Martinez ${ }^{1}$ \\ Amalia Moreno-Torres ${ }^{1}$ \\ Almudena Hernández Núñez ${ }^{1}$
}

\author{
Diego Martinez-Sanchez ${ }^{1}$ \\ Maria Huerta-Brogeras ${ }^{1}$ \\ Jesus Borbujo ${ }^{1}$
}

DOI: http:/ /dx.doi.org/10.1590/abd1806-4841.20153794

\begin{abstract}
A bstract: We report the case of a 35-year-old woman with deep-red asymptomatic macules on the plantar and dorsal skin of the right great toe. Histopathologic findings were compatible with Angioma serpiginosum. Immunohistochemical stains for estrogens and progesterone receptors were negative. Dermoscopy showed an erythematous parallel ridge pattern with double rows of irregular dots and globules. We report an unusual case of angioma serpiginosum with acral volar skin involvement. The dermoscopic features described may aid in the diagnosis of AS in this specific skin area. Acral volar skin involvement must be included in the clinical spectrum of Angioma serpiginosum and in the differential diagnosis of acral vascular lesions.
\end{abstract}

Keywords: Dermoscopy; Hemangioma; Skin diseases, vascular

\section{INTRODUCTION}

Clinical features of angioma serpiginosum (AS) are patches that consist of multiple, small, asymptomatic, non-palpable, deep-red to purple punctate macules organized in small clusters and sheets. The lesions enlarge peripherally and their extension may produce a serpiginous pattern. The extremities are most commonly affected, initially with a unilateral distribution. Palms, soles and mucous membranes are usually not involved. ${ }^{1}$

\section{CASE REPORT}

A 35-year-old woman was referred to our dermatology department for assessment of asymptomatic erythematous skin lesions that had involved the right foot in the previous 5 years. She noted that the lesions had spread from the sole to right great toe during the last year. The patient's and family medical history were unremarkable. Dermatologic examination revealed deep-red macules, with persistence of purple-coloured punctate under diascopy on the right sole (Figure 1A). On the dorsum of the right great toe, a deep-red punctate was observed (Figure 1B). In the acral volar skin, the dermoscopy showed an erythematous parallel ridge pattern with an irregular globular component. The red bands were composed of reddish rows of dots and globules arranged in a double line, and the openings of the acrosiringia were not affected (Figure 2). On the dorsum of the great toe, the dermoscopy showed small, sharply demarcated red lagoons. Blood analysis and foot $\mathrm{x}$-rays were normal. Histopathologic examination revealed multiple areas of glomerulated proliferation of dilated capillaries in the papillary dermis (Figure 3A). The immunohistochemical stains for estrogens and progesterone receptors were negative (Figure 3B). Findings were consistent with the diagnosis of AS. The patient refused any treatment and therefore, we decided to monitor the lesion. 

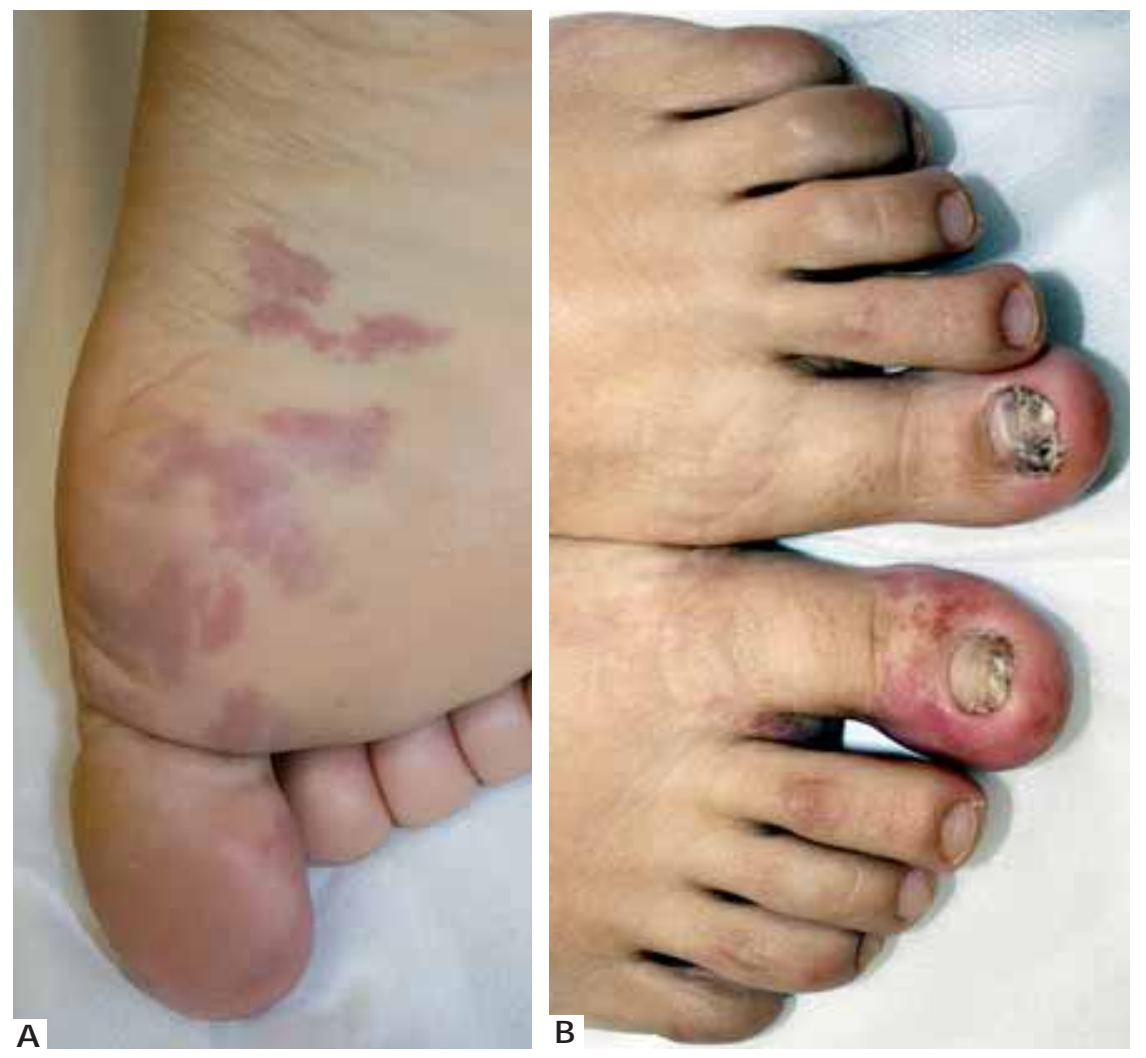

\section{Figure 1:}

A. Clinical features. Deep-red macules, with purple-coloured punctuate macules on the right sole.

B. Clinical features. Deep-red punctuate macules with a serpiginosum pattern are observed on the dorsum of the right great toe

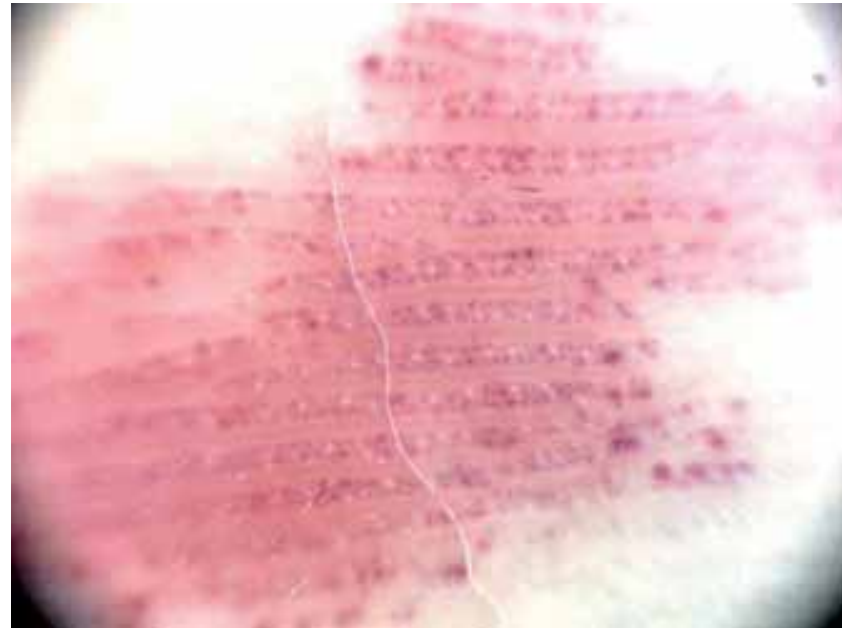

FIGURE 2: Dermoscopy shows an erythematous parallel ridge pattern with an irregular globular component. The red bands are compose of reddish rows of dots and globules arranged in a double line, and the openings of the acrosiringia are not affected

\section{DISAUSSION}

AS is an unusual vascular disorder that typically affects female patients and classically begins in childhood, rarely showing partial or complete regression. It is characterized by multiple, small, asymptomatic, non-palpable, deep-red punctate macules organized

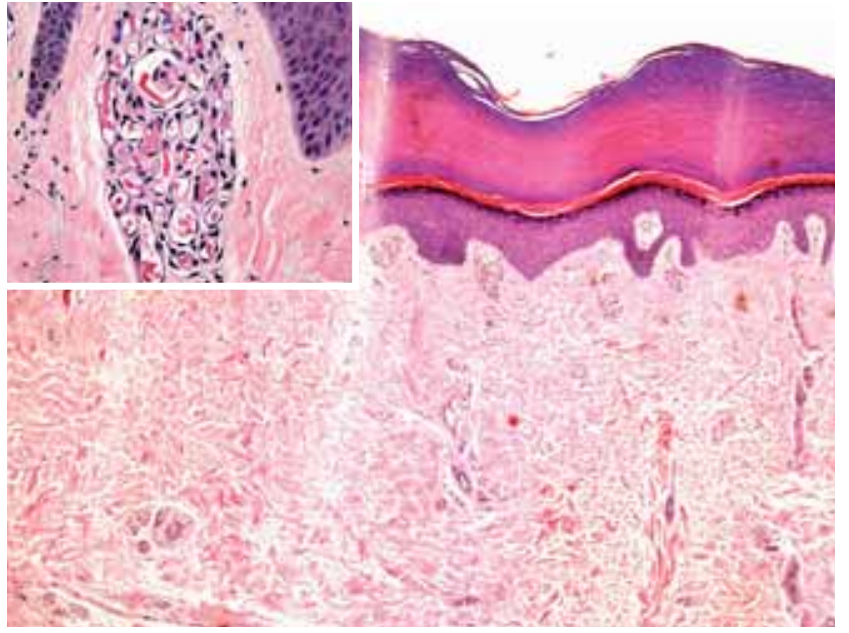

Figure 3: A. Multiple areas of glomerulated proliferation of dilated capillaries in the superficial dermis of the acral skin (H\&E x 100). Inset: glomerulated proliferation of dilated capillaries. B. Negativity of the immunohistochemical stains for estrogens and progesterone receptors (magnification $\times 400$ )

in small clusters and sheets. The arrangement and extension of the lesions may produce a serpiginous pattern and it rarely affects acral volar skin. ${ }^{1}$

A case of AS presenting in an asymmetric, systematized, segmental pattern was reported. This pat- 
TABLE 1: Angioma serpiginosum with acral skin involvement

\begin{tabular}{llllll}
\hline Cases & Age (years) & Sex & Age of onset & Acral skin involved & REFERENCES \\
\hline $1^{*}$ & 35 & F & 30 & Right sole & \\
2 & 16 & M & Early childhood & Left sole & 8 \\
3 & 48 & F & 43 & Left sole & 11
\end{tabular}

*Our case.

tern may reflect cutaneous mosaicism and it has been suggested that AS might be best categorized as a vascular nevus. ${ }^{2}$ However, AS is widely accepted as a capillary malformation with endotelial proliferation and differentiation. ${ }^{3}$

The female predominance, the onset in adolescence and the rapid progression of AS during pregnancy have been implicated as indirect evidence of estrogen dependence. ${ }^{4}$ In our case, immunhistochemical analysis revealed the absence of estrogen and progesterone receptors, as found in others studies, suggesting that there is no hormonal stimulus in the pathogenesis of AS. ${ }^{5,6}$

There are only a few case reports of AS with extensive cutaneous involvement, and some of these have described extensive involvement of the extremities but have not specified any acral volar skin lesions. 7,8 We found two cases with clear acral volar skin involvement in the literature review and both cases compromised the plantar area (Table 1) ${ }^{6,9}$ These cases shared histopathological features and clinical progression with our patient's case.

Many dermoscopic patterns have been reported in vascular disorders and some of these are useful for

\section{REFERENCES}

1. Ohnishi T, Nagayama T, Morita T, Miyazaki T, Okada H, Ohara K, et al. Angioma serpiginosum: a report of 2 cases identified using epiluminescence microscopy. Arch Dermatol. 1999;135:1366-8.

2. Chen W, Liu TJ, Yang YC, Happle R. Angioma serpiginosum arranged in a systematized segmental pattern suggesting mosaicism. Dermatology. 2006;213:236-8.

3. Requena L, Sangueza OP. Cutaneous vascular proliferation. Part II. Hyperplasias and benign neoplasms. J Am Acad Dermatol. 1997;37:887-919.

4. Erbagci Z, Erbagci I, Erkiliç S, Bekir N. Angioma serpiginosum with retinal involvement in a male: a possible aetiological role of continuous cold exposure. J Eur Acad Dermatol Venereol. 2004;18:238-9.

5. Erkek E, Bozdogan 0, Akarsu C, Atasoy P, Koçak M. Absence of estrogen and progesterone receptors around the affected vessels of angioma serpiginosum: case report. Am J Clin Dermatol. 2006;7:383-6.

6. Bayramgurler D, Filinte D, Kiran R. Angioma serpiginosum with sole involvement. Eur J Dermatol. 2008;18:708-9.

7. Sandhu K, Gupta S. Angioma serpiginosum: report of two unusual cases. J Eur Acad Dermatol Venereol. 2005;19:127-8.

8. Katta R, Wagner A. Angioma serpiginosum with extensive cutaneous involvement. J Am Acad Dermatol. 2000;42:384-5. differential diagnosis. The dermoscopy of AS has been described as numerous, small, and relatively well-demarcated round to oval red dots and globules. ${ }^{10}$ These red lagoons in AS reflect the superficial distribution of dilated capillaries in the papillary dermis.

To our knowledge, the dermoscopy patterns of AS affecting acral skin have not been previously described. In our case, the dermoscopy revealed an erythematous parallel ridge pattern with an irregular globular component. The red bands were composed of red rows of dots and globules arranged in a double line, with no involvement of acrosyringia openings. This dermoscopy pattern could be correlated with the glomerulated proliferation of dilated capillaries observed in the papillary dermis.

In conclusion, we report an unusual case of AS with a late plantar onset. The clinical features, progression of the lesions and histopathologic findings confirmed the diagnosis in our patient. The dermoscopic pattern described in the acral skin may aid in the diagnosis of AS in this particular skin area. Acral skin involvement should be included in the clinical spectrum of AS and in the differential diagnosis of acral skin vascular lesions. $]$

9. Chen JH, Wang KH, Hu CH, Chiu JS. Atypical angioma serpiginosum. Yonsei Med J. 2008;49:509-13.

10. Ghanadan A, Kamyab-Hesari K, Moslehi H, Abasi A. Dermoscopy of angioma serpiginosum: a case report. Int J Dermatol. 2014;53:1505-7.

\author{
M AILING ADDRESS: \\ A zael Freites-M artinez \\ CaminodelM olino 2 \\ H ospital U niversitario de Fuenlabrada \\ Servicio de D ermatología. \\ M adrid, Spain. Postal code: 28942 \\ E-mail: azaelfreites@yahoo.com
}

How to cite this article: Freites-Martinez A, Martinez-Sanchez D, Moreno-Torres A, Huerta-Brogeras M, Hernández-Núñez A, Borbujo J. Angioma serpiginosum: report of an unusual acral case and review of the literature. An Bras Dermatol. 2015;90(3 Suppl 1):S26-8. 